Tersedia online di:http://ejournal-balitbang.kkp.go.id/index.php/jkpi
e-mail:jkpi.puslitbangkan@gmail.com
JURNAL KEBIJAKANPERIKANANINDONESIA
Volume 10 Nomor 1 Mei 2018
p-ISSN: 1979-6366
e-ISSN: 2502-6550
Nomor Akreditasi Kementerian RISTEKDIKTI: 21/E/KPT/2018

\title{
KONTRUKSI SOSIAL DALAM MEMBANGUN BISNIS LOBSTER DI INDONESIA
}

\section{SOCIAL CONSTRUCTION ON THE DEVELOPMENT OF LOBSTER BUSINESS IN INDONESIA}

\author{
Armen Zulham*1 \\ 'Balai Besar Riset Sosial Ekonomi Kelautan dan Perikanan, Jl. Pasir Putih I, Ancol Timur, Jakarta Utara-14430, Indonesia \\ Teregistrasi I tanggal: 28 September 2017; Diterima setelah perbaikan tanggal: 03 Maret 2018; \\ Disetujui terbit tanggal: 19 Mei 2018
}

\begin{abstract}
ABSTRAK
Konstruksi sosial bisnis lobster merupakan fenomena sosial yang berperan menjaga keberlanjutan bisnis lobster. Peran itu telah ditunjukkan melalui berbagai regulasi dan kelembagaan (asosiasi lobster) di Amerika Utara, Australia dan Uni Eropa. Di Indonesia asosiasi atau organisasi yang demikian belum ada. Keberadaan Permen KP No. 56/ 2016, merupakan konstruksi sosial yang penting untuk merintis pengembangan bisnis lobster Indonesia yang berkelanjutan. Tulisan ini mempelajari fenomena kontruksi sosial dari jaringan sosial bisnis lobster pada berbagai kawasan di Indonesia. Bahan tulisan ini, diperoleh dari studi pustaka, hasil survey di Simeulue tahun 2015 - 2016 dan wawancara narasumber yang terkait langsung dengan bisnis lobster pada bulan Juli 2017. Hasil analisis menunjukkan kebijakan terobosan harus dilakukan dalam mengembangkan bisnis lobster di Indonesia dengan membentuk kelembagaan Asosiasi Lobster Indonesia (ALI) atau Konsorsium Lobster Indonesia (KLI). ALI atau KLI berperan tidak hanya untuk berdagang, tetapi membantu pemerintah menjaga stok lobster dan mempromosikan teknik penangkapan/budidaya lobster, serta merancang kebijakan untuk mempengaruhi pasar global.
\end{abstract}

Kata Kunci: Lobster; kontruksi sosial; perdagangan; pasar global

\section{ABSTRACT}

Social construction of lobster business is a social phenomenon to maintain the sustainability of lobster business. The role has been showed by many regulations and institutions (lobster associations) in North America, Australia and European Union. Such associations have not been established in Indonesia. The Ministerial Regulation of Fisheries \& Marine Affair No. 56/2016 is an important social construction as a pioneer to develop of sustainable lobster business in Indonesia. This paper studied the phenomenon of social construction from lobster business network in many areas in Indonesia. Data and information were obtained from literature study, survey in Simeulue from 2015-2016, and interview with source remains directly related with lobster business in July 2017. Result of the analysis showed that an innovation in Indonesian lobster business policies should be made by creating Indonesian Lobster Association (ILA) or Indonesian Lobster Consortium (KLI). The role of ILA or KLI are not only related to lobster trading, but also to assist the government in maintaining lobster stock, promoting techniques of lobster cultivation, and designing policies to affect global market.

Keywords: Lobster; social construction; trade; global market 


\section{PENDAHULUAN}

Perdagangan lobster dunia pada tahun 2014 telah mencapai 170.156 ton (Pereira \& Josupeit, 2017). Jumlah tersebut: $32,2 \%$ berasal dari Kanada; 30,4\% dari Amerika Serikat; 7,1\% dari Indonesia; 4,9\% dari Australia serta $9,9 \%$ dari sisanya negara Karibia (FAO, 2015). Dua negara pertama, merupakan pasar utama lobster dunia dan bisnisnya dikawal dengan kontruksi sosial yang solid, agar stok lobster di perairan terjaga dan investasi serta bisnis lobster terjamin dan berkembang.

Lobster yang diperdagangkan pada pasar global menurut Hart (2009) dan Jones (2010) terdiri dari jenis: european lobster - Homarus gammarus (2,0\%), rock lobster- Jasus spp. (3,9\%), spiny lobster-Panulirus spp. $(32,7 \%)$, dan american lobster - Homarus americanus $(61,4 \%)$.

Sebagai salah satu pemasok spiny lobster ke pasar global, produksi lobster Indonesia pada tahun 2013 sekitar 16.482 ton (FAO, 2015). Produksi itu, berasal dari perairan Pulau Sebatik (Chodrijah et al., 2018); perairan Gorontalo \& Sulawesi Utara; perairan Maluku Utara; perairan Sulawesi Tengah \& Sulawesi Selatan (DJPB, 2013). Pasokan utama untuk pasar global adalah dari perairan barat Sumatera (Romdhon \& Sukiyono, 2011; Nasution et al., 2015; Zulham \& Nasution, 2016) yang didominasi oleh: P. penicilatus (32,8\%), P. versicolor (22,9\%), P. longipes (13,1\%), $P$. homarus (22,4\%) dan Parribus antarticus (14,2\%); dari perairan selatan Jawa (Setyono, 2006; Suantika et al., 2017; Damora, 2016; Nasution et al., 2015; Wardiatno et al., 2016; Permana, 2017) yang didominasi jenis lobster: $P$. penicilatus (55\%), $P$. homarus (39\%); dan perairan Lombok (Williams, 2009; Jones, 2015; Kalih, 2012; Erlania et al., 2014; Witomo \& Nurlaili, 2015), yang terdiri dari P. homarus (90\%) dan P. ornatus (10\%).

Pada sentra lobster di Lombok (Nurfiarini \& Purnamaningtyas, 2017; Erlania et al., 2014) dan di Simeulue (Zulham \& Nasution, 2016), serta pada perairan selatan Jawa pasokan spiny lobster untuk pasar terus berkurang, akibat penangkapan yang tidak terkendali. Hal ini terjadi, karena pelaku usaha masih mengabaikan peran kontruksi sosial (kebijakan, aturan dan organisasi) pada bisnis lobster. Jika pasokan tersebut terus berkurang, maka kontribusi Indonesia pada pasar lobster global akan terganggu.

Peraturan Menteri Kelautan dan Perikanan (Permen KP) No. 1/PERMEN-KP/ 2015 dan disempurnakan dengan Permen KP No. 56/PERMEN$\mathrm{KP} / 2016$ merupakan awal pengendalian bisnis lobster di Indonesia. Kemudian, restocking merupakan gagasan untuk memulihkan stok lobster (Nurfitriani et al., 2016).

Permen KP No.56/PERMEN-KP/2016, adalah kontruksi sosial yang melarang transaksi Panulirus spp., dalam bentuk benih untuk budidaya, lobster bertelur dan lobster ukuran karapas $<8 \mathrm{~cm}$ atau berat $<200$ gram per ekor. Kontruksi sosial tersebut tidak direspon positif oleh pelaku usaha pada beberapa daerah. Disparitas harga lobster yang lebar antara produsen dan pasar adalah penyebabnya (Damsar \& Indrayani, 2018). Akibatnya, bisnis benih lobster illegal sering terjadi, penangkapan lobster < 200 gram per ekor dan lobster bertelur oleh nelayan masih ditemukan. Selain itu, pelaku usaha yang telah mendapat "rente ekonomi" yang besar pada jaringan sosial bisnis itu tidak ingin berintegrasi membentuk organisasi/asosiasi untuk merumuskan kesepakatan dalam melaksanakan permen tersebut, karena pangsa pasar dan "rente ekonomi" mereka akan terganggu.

Pada sisi lain, restocking lobster yang dilakukan pada beberapa perairan di Indonesia (Nurfitriani et al., 2016), kontruksi sosial untuk melakukannya tidak pernah disiapkan. Kelembagaan formal dan non formal yang dinilai oleh Nurfitriani et al., (2016) dapat membantu restocking, ternyata tingkat partisipasinya insentif (Pretty, 1995), sehingga berkontribusi membuat rencana tersebut tidak berhasil.

Tujuan tulisan ini adalah untuk mempelajari kontruksi sosial dalam pengelolaan bisnis lobster di Indonesia, agar bisnis dan perdagangan lobster Indonesia berkembang.

Data dan informasi untuk tulisan ini bersumber dari studi pustaka dan hasil penelitian yang terkait dengan lobster. Informasi tambahan diperoleh dari pelaku usaha di Simeulue dan Gunung Kidul serta petugas Karantina Ikan antara tahun 2015-2017. Analisis data dan informasi dilakukan dengan pendekatan Cross Cutting Analysis - CCA (OECD, 2014 dan Campbell et al., 2013). CCAdilakukan untuk mempelajari trace element(kebijakan / aturan/ organisasi) pada sumber informasi (negara yang telah berkembang bisnis lobsternya) dengan target memperbaiki bisnis lobster di Indonesia. Hasil analisis tersebut dielaborasi secara deskriptif, sehingga knowledge yang diperoleh dapat dipertimbangkan dalam pengembangan bisnis lobster di Indonesia.

\section{BAHASAN \\ RUANG LINGKUP KONSTRUKSI SOSIAL BISNIS LOBSTER}

Kontruksi sosial bisnis lobster merupakan fenomena sosial dalam bentuk kebijakan / aturan / 
organisasi yang digunakan untuk mengintervensi kehidupan sosial dan kultural masyarakat yang terkait dengan bisnis tersebut. Dari intervensi itu, diperoleh pengetahuan jangka panjang tentang prospek pemanfaatan potensi lobster pada perairan, peluang ekonomi, sosial dan budaya, sehingga potensi bisnis lobster dapat dioptimalkan. Mengikuti pemikiran Radcliffe-Brown (1940), kontruksi sosial bisnis lobster seperti itu merupakan upaya intervensi struktur sosial yang ada, agar jaringan sosial serta koalisi sosial dalam bisnis lobster selaras dengan kebijakan / aturan yang dibuat. Kekuatan jaringan sosial dan koalisi sosial tersebut dapat mengendalikan produksi dan meningkatkan pangsa pasar. Kekuatan itu terbentuk dari kepatuhan komunitas bisnis tersebut melaksanakan kebijakaan, aturan serta kesepakatan organisasi.

Kontruksi sosial komunitas bisnis lobster itu, akan memiliki bargaining position dalam menjalankan dan mengembangkan bisnis lobster yang berkelanjutan. Implementasi bisnis lobster yang demikian dilakukan melalui: kebijakan, mengikuti produk hukum yang terkait dengan berbagai aspek dalam bisnis lobster. Aturan, dilaksanakan mengikuti kesepakatan atau aturan yang dibuat oleh lembaga non pemerintah yang terkait dengan bisnis lobster. Organisasi, diwujudkan dalam asosiasi/lembaga dibentuk untuk menjamin transaksi lobster yang diperdagangkan itu, dihasilkan melalui proses produksi yang benar (good management practice).

\section{KONSTRUKSI SOSIAL BISNIS LOBSTER DALAM PASAR GLOBAL}

\section{Kebijakan (Policy Regulation)}

Di Amerika Serikat, Kanada, negara Uni Eropa dan Australia, perikanan lobster merupakan bisnis penting. Oleh sebab itu, pada negara tersebut dibuat kebijakan untuk menjaga keberlanjutan bisnis lobster itu. Subtansi kontruksi sosial dari kebijakan pada negara tersebut dapat dipelajari pada Tabel 1.

Tabel 1. Kebijakan dalam menjaga keberlanjutan bisnis lobster di AS, Kanada, Uni Eropa dan Australia. Table 1. Policy to maintain sustainability of lobster business in US, Canada, European Union and Australia

\begin{tabular}{|c|c|c|c|c|}
\hline $\begin{array}{l}\text { Deskripsi / } \\
\text { Description }\end{array}$ & $\begin{array}{c}\text { Amerika Serikat / } \\
\text { United State of } \\
\text { America }\end{array}$ & Kanada / Canada & $\begin{array}{c}\text { Uni Eropa /. } \\
\text { European } \\
\text { Union }\end{array}$ & $\begin{array}{l}\text { Australia / } \\
\text { Australia }\end{array}$ \\
\hline $\begin{array}{l}\text { Produk Hukum } \\
\text { / Regulation } \\
\text { Products }\end{array}$ & $\begin{array}{l}\text { Undang-Undang / } \\
\text { Law }\end{array}$ & $\begin{array}{l}\text { Undang-undang / } \\
\text { Law }\end{array}$ & $\begin{array}{l}\text { Undang-undang } \\
\text { / Law }\end{array}$ & $\begin{array}{l}\text { Undang-undang / } \\
\text { Law }\end{array}$ \\
\hline $\begin{array}{l}\text { Sasaran / } \\
\text { Targets }\end{array}$ & $\begin{array}{l}\text { Asosiasi produsen, } \\
\text { pengolah, } \\
\text { pedagang lobster / } \\
\text { Producer, } \\
\text { processor and } \\
\text { trader of lobster } \\
\text { associations. }\end{array}$ & $\begin{array}{l}\text { Forum Lobster / } \\
\text { The Forum of } \\
\text { Lobster Council of } \\
\text { Canada }\end{array}$ & $\begin{array}{l}\text { Pedagang } \\
\text { Lobster / } \\
\text { Lobster Traders }\end{array}$ & $\begin{array}{l}\text { Penangkap lobster } \\
\text { komersial dan } \\
\text { rekreasi / The } \\
\text { Lobster fishermen } \\
\text { and Recreational } \\
\text { fishermen }\end{array}$ \\
\hline $\begin{array}{l}\text { Bentuk } \\
\text { intervensi / Tipe } \\
\text { of interventions }\end{array}$ & $\begin{array}{l}\text { Pengaturan ukuran } \\
\text { perdagangan } \\
\text { lobster, aturan } \\
\text { perdagangan } \\
\text { lobster beku, lisensi } \\
\text { / Restriction on the } \\
\text { size of lobster } \\
\text { trade, possession of } \\
\text { frozen lobster, } \\
\text { licences }\end{array}$ & $\begin{array}{l}\text { Advokasi, } \\
\text { membangun } \\
\text { akses pasar, } \\
\text { promosi bersama } \\
\text { dengan industri / } \\
\text { Advocation, } \\
\text { develop market } \\
\text { access and } \\
\text { promotion with } \\
\text { industries }\end{array}$ & $\begin{array}{l}\text { Pengaturan } \\
\text { lobster yang } \\
\text { diperdagangkan, } \\
\text { aturan dalam } \\
\text { budidaya lobster } \\
\text { / Restriction on } \\
\text { lobster trade, } \\
\text { rule in lobster } \\
\text { culture }\end{array}$ & $\begin{array}{l}\text { Konservasi } \\
\text { populasi lobster, } \\
\text { mengatur jumlah } \\
\text { yang ditangkap / } \\
\text { Conservation of } \\
\text { lobster population, } \\
\text { prepare number of } \\
\text { lobster catch }\end{array}$ \\
\hline
\end{tabular}

Sumber: $\quad$ Marine Fisheries Commonwealth of Massachusetts, 2012), Common Fisheries Policy, 2017, Departement of Fisheries Government of Western Australia, 2014) dan The Lobster Council of Canada. (2017).

Sources: Marine Fisheries Commonwealth of Massachusetts, (2012), Common Fisheries Policy, 2017, Departement of Fisheries Government of Western Australia, (2014) dan The Lobster Council of Canada. (2017) 
Kebijakan bisnis lobster di Amerika Serikat sampai tahun 1970-an, dibuat untuk mengatur pemanfaatan dan pengelolaan potensi Maine Lobster Fishery (Dow et al., 1975 dan Bell, 1978). Pada tahun 2000-an, kontruksi sosial kebijakan lobster semakin maju, kebijakan semakin luas termasuk skema pemanfaatan potensi lobster, perdagangan lobster olahan, penggunaan lobster beku untuk pangan, perdagangan dan pasar (Marine Fisheries Commonwealth of Massachusetts, 2012).

Common Fisheries Policy (CFP) adalah salah satu contoh kontruksi sosial, yang diarahkan untuk mengatur berbagai aspek tentang perdagangan lobster, aturan dalam budidaya lobster, sehingga melindungi populasi lobster (Common Fisheries Policy, 2017). Kebijakan ini, mengikat seluruh stakeholder dari berbagai negara yang berdagang lobster dengan negara negara Uni Eropa. Regulasi ini, menciptakan iklim bisnis lobster yang adil, berkelanjutan dan mendorong proses produksi lobster dilakukan dengan prinsip good management practice.

Di Australia, Fish Resources Management Act (1994) merupakan kebijakan untuk melindungi West Coast Rock Lobster Fishery. Kebijakan tersebut dilaksanakan melalui konservasi potensi perikanan termasuk lobster (Departement of Fisheries Government of Western Australia, 2014), mengatur jumlah lobster yang boleh ditangkap oleh perusahaan lobster komersial dan recreational fishing berdasarkan prinsip Integrated Fisheries Management dan Harvest Strategy and Control Rules (Departement of Fisheries Government of Western Australia, 2013).

Kontruksi sosial melalui kebijakan, dapat juga sebagai penghambat dan pendorong perkembangan bisnis lobster. Kebijakan restriksi perdagangan adalah kontruksi sosial yang menghambat perdagangan lobster. Tindakan larangan impor American lobster oleh Uni Eropa merupakan bentuk kebijakan non tarif yang mempengaruhi bisnis lobster di Amerika dan Canada (Overton, 2016). Kebijakan non tariffini dibuat karena ditemukan lobster jenis $H$. americanus pada perairan negara-negara UE. Spesies tersebut mengancam populasi $H$. gammarus pada perairan UE (terutama di Swedia). Kebijakan yang demikian menurut Arabiun (2010) disebut sebagai "weak social construction". Inflasi adalah bentuk lain dari "weak social construction". Di Amerika Utara, Uni Eropa serta Cina, kebijakan pendorong inflasi meyebabkan turunnya daya beli masyarakat, akibatnya konsumsi lobster berkurang dan pasar kelebihan suplai lobster sehingga harga lobster menurun (Globefish Highlight, 2017).

\section{Aturan}

Kontruksi sosial dalam bentuk aturan (rule) pada Tabel 2, dibuat oleh lembaga non pemerintah yang berpengaruh dalam perdagangan global seperti Marine Stewardship Council (2015). Lembaga ini, membuat aturan dan melakukan kajian serta memberikan sertifikasi pada pengguna yang terlibat dalam bisnis/ perdagangan lobster. Sertifikasi ini tidak mengikat, tetapi wajib jika pengguna melakukan perdagangan lobster dalam jaringan super market global / global retail di Amerika Utara, Uni Eropa dan Australia.

Kelompok usaha yang telah mempunyai sertifikasi dijamin mendapat akses ke pasar lobster pada jaringan retail pada negara-negara tersebut. Sertifikasi ini secara tidak langsung mendorong pengusaha menghasilkan lobster dengan pendekatan good management practice.

\section{Organisasi}

Organisasi dalam bentuk asosiasi disebut Berger \& Luckmann (1966) sebagai kontruksi sosial untuk menjamin investasi dan menyelesaikan hambatan perdagangan. Organisasi bisnis lobster yang demikian umumnya terdapat di Amerika Utara seperti Maine Lobster Association, The Lobster Council of Canada; di Uni Eropa seperti Irish Sea Fisheries Board (BIM, 2010); Australia - Western Rock Lobster Council Australia (Davies, 2006). Kontruksi sosial dalam bentuk asosiasi menurut Davies (2006) efektif mengendalikan effort penangkapan lobster dan menyelesaikan sengketa dagang agar bisnis lobster anggotanya tetap berkembang.

Peran dan efektivitas kontruksi sosial dari sisi organisasi pada pasar global dapat dipelajari, misalnya dari kasus antara organisasi EU scientific commission dengan Maine Lobster Association tentang $\mathrm{H}$. americanus yang disebut sebagai spesies invasive di perairan Eropa oleh Swedia (Overton, 2016). Pada kasus tersebut, asosiasi berguna dalam negosiasi permasalahan dagang, agar label spesies invasive pada jenis $H$. americanus dari negara Uni Eropa dihilangkan. Negosiasi itu, mendorong perdagangan lobster dari Amerika Utara ke Eropa dilakukan tanpa hambatan, serta lobster spesies $H$. gammarus asli Eropa dapat dilindungi dan menjadi komoditas binis yang berkembang.

Dengan demikian asosiasi lobster adalah kontruksi sosial dalam bentuk organisasi yang dapat disebut sebagai "strong social construction" (Arabiun, 2010). Peran dan efektivitasnya organisasi tersebut sangat jelas dalam pengembangan bisnis lobster pada pasar global. 
Tabel 2. Bentuk kontruksi sosial pada bisnis lobster di pasar global

Table 2. Types of social construction on lobster business in the global market

\begin{tabular}{|c|c|c|}
\hline Sifat / Characteristics & Peran / Roles & Tujuan / Objectives \\
\hline \multicolumn{3}{|c|}{ Kebijakan / Policy Regulation } \\
\hline $\begin{array}{l}\text { Mengikat seluruh stakeholder } \\
\text { yang berbisnis lobster / Binds to } \\
\text { all stakeholders involving in } \\
\text { lobster business }\end{array}$ & $\begin{array}{l}\text { Menciptakan bisnis lobster } \\
\text { berkelanjutan / ensure } \\
\text { sustainable lobster fisheries }\end{array}$ & $\begin{array}{l}\text { Menjamin pendapatan dan } \\
\text { melindungi pekerjaan nelayan } \\
\text { lobster / Guarantee incomes } \\
\text { and stable jobs for lobster } \\
\text { fishermen }\end{array}$ \\
\hline \multicolumn{3}{|c|}{ Aturan / Rule } \\
\hline $\begin{array}{l}\text { Tidak mengikat, tetapi wajib pada } \\
\text { jaringan perdagangan tertentu./ } \\
\text { Non-binding but compulsory on } \\
\text { particular trade network }\end{array}$ & $\begin{array}{l}\text { Sertifikasi bisnis lobster / } \\
\text { Lobster business certification }\end{array}$ & $\begin{array}{l}\text { Menjamin akses pasar dan } \\
\text { mendorong pengelolaan yang } \\
\text { baik dalam bisnis lobster / } \\
\text { ensure market access and } \\
\text { good management practices } \\
\text { lobster business. }\end{array}$ \\
\hline \multicolumn{3}{|c|}{ Organisasi / Institution } \\
\hline $\begin{array}{l}\text { Mengikat, dan wajib mengikuti } \\
\text { aturan organisasi / Binding, and } \\
\text { required to follow organization } \\
\text { rules }\end{array}$ & $\begin{array}{l}\text { Mengatur bisnis lobster, } \\
\text { investasi \& memperlancar } \\
\text { perdagangan lobster / } \\
\text { Regulating lobster business, } \\
\text { investment \& facilitate lobster } \\
\text { trade }\end{array}$ & $\begin{array}{l}\text { Mengatur effort penangkapan } \\
\text { dan menyelesaikan sengketa } \\
\text { dagang dan pengembangan } \\
\text { bisnis / Regulating effort of } \\
\text { catching and resolving trade } \\
\text { dispute and business } \\
\text { development }\end{array}$ \\
\hline
\end{tabular}

Sumber: Analisis dari berbagai sumber: BIM, (2010), Davies (2006) dan Marine Stewardship Council (2015).

Source: Analysis based on various source: BIM, (2010), Davies (2006) dan Marine Stewardship Council (2015).

\section{KONTRUKSI SOSIAL DALAM MEMBANGUN BISNIS LOBSTER INDONESIA}

Sebagai pemasok spiny lobster ke pasar global, maka bisnis lobster di Indonesia harus berkembang dan berkelanjutan. Oleh sebab itu, kontruksi sosial bisnis lobster di Indonesia harus dibangun melalui komparasi (cross cutting analysis) dengan kontruksi sosial bisnis lobster pasar global. Knowledgeyang dihasilkan dari komparasi tersebut diharapkan dapat memperbaiki kelemahan pengembangan bisnis lobster di Indonesia. Uraian berikut adalah cross cutting analysistentang bisnis lobster di Indonesia dengan pokok bahasan kontruksi sosial, seperti yang telah diuraikan sebelumnya.

\section{Kebijakan (Policy Regulation)}

Kontruksi sosial dalam bentuk kebijakan telah dilakukan pemerintah dengan menerbitkan regulasi dalam bentuk Peraturan Menteri Kelautan. Peraturan Menteri Kelautan dan Perikanan No. 56/PERMENKP/2016, menggantikan Peraturan Menteri Kelautan dan Perikanan No. 1/ PERMEN-KP/ 2015. Gagasan restocking lobster belum disebut sebagai kebijakan. Namun, permen dan gagasan tersebut tingkatnya berbeda dengan produk regulasi pada negara-negara yang disebutkan diatas.

Tabel 3. Kontruksi sosial memperkuat keberlanjutan bisnis lobster di Indonesia

Table 3. Social construction to strengthen the sustainable lobster business in Indonesia

\begin{tabular}{|c|c|c|}
\hline $\begin{array}{l}\text { Deskripsi / } \\
\text { Description }\end{array}$ & $\begin{array}{c}\text { Kebijakan dalam penangkapan dan } \\
\text { perdagangan / Policy on cacth and } \\
\text { trade }\end{array}$ & $\begin{array}{c}\text { Kebijakan dalam menjaga } \\
\text { populasi / Policy to conserve } \\
\text { population }\end{array}$ \\
\hline $\begin{array}{l}\text { Produk hukum/ } \\
\text { Regulation products }\end{array}$ & $\begin{array}{l}\text { Peraturan Menteri Kelautan dan } \\
\text { Perikanan / Ministerial Marine and } \\
\text { Fisheries Affairs Act }\end{array}$ & Gagasan / idea \\
\hline Sasaran / Target & $\begin{array}{l}\text { Nelayan dan Pedagang Lobster / } \\
\text { Fishermen and Lobster Traders }\end{array}$ & $\begin{array}{l}\text { Perairan tertentu / Certain sea } \\
\text { area }\end{array}$ \\
\hline $\begin{array}{l}\text { Bentuk intervensi / } \\
\text { Type of interventions }\end{array}$ & $\begin{array}{l}\text { Melarang penangkapan lobster dengan } \\
\text { spesifikasi tertentu / restrict to catch } \\
\text { lobster with certain specification }\end{array}$ & $\begin{array}{l}\text { Menambah jumlah lobster / } \\
\text { restocking lobster }\end{array}$ \\
\hline
\end{tabular}

(2017). 
Permen KP No. 56/PERMEN-KP/2016, sasarannya hanya mengikat nelayan penangkap lobster dan pedagang lobster pada berbagai level di Indonesia. Peran Peraturan Menteri Kelautan dan Perikanan itu, efektif untuk menjaga dinamika populasi spiny lobster (karena lobster yang boleh ditangkap dan diperdagangkan keluar Indonesia adalah tidak dalam kondisi bertelur dan panjang carapas diatas $8 \mathrm{~cm}$ atau berat diatas 200 gram per ekor). Kebijakan tersebut, menjamin pertumbuhan populasi lobster (growth), jumlah lobster yang lahir (recruit) dan kematian alami (natural growt) tergantung pada kondisi alam.

Kontruksi sosial yang dibangun melalui Permen $\mathrm{KP}$ itu, diharapkan dapat melindungi keberlanjutan usaha penangkapan lobster. Namun, perlu dicatat berdasarkan informasi lapangan (2015-2016), bisnis lobster itu berkembang soliter, dikendalikan oleh pedagang besar dengan jaringan sosial tertutup. Jaringan sosial tersebut cenderung menangkap lebih, karena didorong oleh disparitas harga lobster yang diterima nelayan dengan harga pasar (yang diterima pedagang besar) sangat tinggi (Zulham et al., 2015). Sebagai contoh disparitas harga lobster asal Simeulue dan Gunung Kidul pada tahun 2015 - 2016 yang diterima nelayan (rata-rata Rp. 120.000 per kg) dan diterima pedagang besar Jakarta (rata rata $\mathrm{Rp}$. 1.500.000 per kg). Disparitas harga ini mencapai 12,5 kali lipat. Disparitas harga terjadi juga pada benih lobster di tingkat nelayan di dalam negeri dan pasar ekspor. Disparitas harga benih lobster tersebut mendorong perdagangan illegal benih spiny lobster dari Indonesia ke Vietnam. Padahal, perdagangan lobster ukuran benih dan budidaya lobster dilarang oleh Permen KP No. 56/PERMEN-KP/2016.

\section{Aturan}

Di Indonesia belum tercatat terdapat asosiasi atau kelompok dagang yang dapat bekerja sama dengan pemerintah membuat aturan secara nasional dan mempengaruhi perdagangan lobster di pasar global. Pada sentra produksi lobster hanya terdapat Kelompok Masyarakat Pengawas (Pokmaswas), yang mengawasi implementasi regulasi, dan aturan formal seperti Peraturan Menteri Kelautan dan Perikanan No. 56/PERMEN-KP/2016, serta hukum adat (spesifik lokasi).

Hubungan antar stakeholder (nelayan penangkap lobster dan pedagang) berdasarkan responden di Simeulue dan Gunung Kidul bersifat "quasi-integrasi" dan aturan yang dibuat sangat normatif atas dasar kepercayaan untuk kepentingan bisnis mereka. Kontruksi sosial yang demikian, merupakan pola bisnis tradisional atas dasar kepercayaan dan saling membutuhkan (Saptana \& Ashari, 2007). Agar bisnis lobster Indonesia berpengaruh pada pasar global diperlukan wadah untuk menghimpun pedagang lobster tersebut. Wadah itu dapat menyusun dan melaksanakan berbagai aturan yang terkait dengan bisnis lobster serta memfasilitasi berbagai aturan yang ditetapkan pasar global.

Wadah tersebut menjadi pendorong, agar sertifikasi perlu dimiliki oleh pelaku bisnis lobster Indonesia. Pedagang lobster Indonesia yang telah memiliki sertifikasi global (seperti Marine Stewardsip Council) dapat memasok lobster langsung ke jaringan retail pasar global, tanpa kehilangan peluang memasok lobster ke pedagang besar lobster di Hong Kong, Taiwan dan China (yang tidak memerlukan sertifikasi Marine Stewardsip Council, karena pasar domestik negara itu tidak mensyaratkan sertifikasi tersebut).

Saat ini, akses langsung pedagang lobster Indonesia ke jaringan super market global di Amerika Utara dan Uni Eropa - (pengimpor lobster terbesar di dunia) - harus melalui pihak ketiga yang telah memiliki sertifikasi Marine Stewardship Council. Keadaan ini terjadi karena iklim perdagangan lobster yang dilakukan oleh pedagang besar lobster Indonesia bersifat soliter.

Oleh sebab itu, untuk mendapat akses langsung ke pasar lobster yang luas di Amerika Utara dan Uni Eropa, pedagang besar Indonesia harus mengajukan assessment sertifikasi ke Marine Stewardship Council. Assessment seperti ini dilakukan oleh asesor terpercaya. Assessment Marine Stewardship Council mencakup 7 tahap dengan waktu yang lama sehingga membutuhkan biaya yang besar (Marine Stewardship Council, 2015). Biaya ini tidak mungkin menjadi beban satu atau dua pedagang besar lobster. Sumber biaya untuk mendapat sertifikasi itu adalah dari beberapa pengusaha lobster yang dihimpun dalam wadah pedagang lobster.

\section{Organisasi}

Di Indonesia belum ada kontruksi sosial dalam bentuk organisasi seperti asosiasi lobster di Amerika Utara, Uni Eropa serta Australia. Kontruksi sosial pada negara itu berfungsi: (a). Melakukan advokasi pada pelaku usaha lobster terkait dengan permasalahan bisnis lobster di pasar domestik dan manca negara; (b). Merintis dan membangun akses pasar ke berbagai pasar manca negara; (c). Melakukan penelitian dan mengelola effort pemanfaatan stok lobster, dan (d). Bekerja sama dengan industri untuk promosi dan pemasaran lobster. 
Kontruksi sosial dalam bentuk organisasi yang ada di Indonesia adalah untuk mengawal dan mengeksekusi Peraturan Menteri Kelautan dan Perikanan No. 56/ PERMEN-KP/2016. Organisasi / intitusi itu antara lain terdiri dari organisasi formal yaitu unit kerja: lingkup Badan Karantina Ikan dan Pembinaan Mutu Perikanan, Pengawas Sumber Daya Kelautan Perikanan, Polisi Air, Bea dan Cukai serta organisasi non formal seperti Kelompok Masyarakat Pengawas (Pokmaswas). Organisasi formal dan non formal tersebut tugasnya adalah untuk mengawal penangkapan dan perdagangan lobster mengikuti Peraturan Menteri Kelautan dan Perikanan tersebut. Organisasi formal tersebut, hanya bekerja untuk mengawal berbagai regulasi dan tugas pokok serta fungsinya tidak mendorong ekspansi bisnis lobster ke pasar global.

Oleh sebab itu, peningkatan peran Indonesia pada pasar lobster global, memerlukan kontruksi sosial lain. Pengusaha lobster Indonesia perlu membentuk organisasi/ asosiasi lobster, seperti di Amerika Utara, Uni Eropa dan Australia. Organisasi /asosiasi ini tidak hanya berinovasi dalam perdagangan lobster, tetapi ikut berperan membantu pemerintah menentukan inovasi pengembangan bisnis lobster mulai di hulu sampai ke hilir, sesuai dengan preferensi pasar. Asosiasi / organisasi akan mewarnai bisnis lobster di Indonesia dengan 3 prinsip, yaitu: menjamin lapangan kerja, meningkatkan pendapatan dan menjaga kelanjutan investasi dan usaha.

Asosiasi tersebut diharapkan berperan: (a). Melakukan advokasi untuk menyempurnakan Permen KP No.56/PERMEN-KP/2016, dengan jaminan bisnis lobster Indonesia dilakukan dengan 3 prinsip diatas. (b). Memperkenalkan pengembangan bisnis lobster menggunakan inovasi perangkap (trap). Inovasi ini memiliki keunggulan seperti: membuka lapangan kerja baru pada simpul produksi dan perdagangan, menjamin keberlanjutan potensi lobster. (c). Melakukan sertifikasi lobster asal Indonesia yang diperdagangkan ke pasar global menurut asal perairan dan sesuai dengan ukuran/permintaan pasar.

Mengacu pada hasil cross cutting analysis yang diuraikan diatas, Indonesia dapat berperan memasok langsung ke jaringan pasar retail global di Amerika Utara, Uni Eropa dan Australia. Oleh sebab itu, kebijakan lanjutan harus dirancang pemerintah Indonesia untuk mendorong pengusaha (pedagang besar) lobster di Indonesia bergabung membentuk organisasi dalam bentuk asosiasi atau konsorsium industri lobster (sebut saja Asosiasi Lobster Indonesia - ALI atau Konsorsium Lobster Indonesia - KLI) - untuk mengatasi biaya yang besar dalam mendapat sertifikasi perdagangan.

ALI atau KLI menjadi wadah untuk pengembangan produksi dan memfasilitasi perdagangan lobster yang bersertifikat agar pedagangan lobster Indonesia ke jaringan retail global di Amerika Utara, Uni Eropa dan Australia diakui dan tidak melalui pihak ketiga. ALI atau KLI dirancang juga bersinergi dengan pemerintah melakukan advokasi peraturan pemerintah kepada produsen lobster, membangun akses pasar, mengelola effort pemanfaatan stok lobster berdasarkan hasil kajian dan membangun kerjasama dengan industri serta promosi lobster kepada pelaku usaha lobster lain (jaringan restoran siap saji) seperti yang dikatakan Josupeit et al., (2017).

Jika $\mathrm{ALI}$ atau KLI yang bersertifikat itu, terbentuk dalam industri/bisnis lobster di Indonesia, maka kontruksi sosial tersebut dapat berperan membangun dan mengembangkan: (a). Kluster bisnis/industri lobster $P$. penicillatus, $P$. versicolor dan Parribacus antarticus pada perairan barat Sumatera, (perairan pantai barat Aceh dan Bengkulu). (b) Kluster bisnis/ industri lobster $P$. homarus dan $P$. ornatus pada perairan Pulau Lombok. (c). Kluster bisnis /industri lobster $P$. penicillatus dan $P$. homarus pada perairan pantai selatan Jawa. Kluster bisnis/industri lobster yang dikembangkan ALI atau KLI tersebut menjadi modal untuk mendapat sertifikasi internasional yang terkait dengan bisnis lobster. Selain itu, gejolak sosial pada komunitas bisnis lobster dapat dikendalikan karena peran ALI dan KLI tersebut.

\section{KESIMPULAN DAN REKOMENDASI Kesimpulan}

Pemahaman tentang kontruksi sosial bisnis lobster pada pasar global melalui kebijakan (policy regulation), aturan (rule) dan organisasi (institution) memberi wawasan bahwa untuk mengembangkan bisnis lobster di Indonesia diperlukan strategi. Hal ini disebabkan pasar lobster terbesar dunia (Amerika Serikat dan Uni Eropa) telah dikuasai oleh jaringan "kartel" pasar retail global moderen yang menerapkan sertifikasi pada pelaku usaha dalam perdagangan lobster (Marine Stewardship Council). Sertifikasi yang demikian hanya mampu diperoleh asosiasi lobster seperti: Maine Lobster Association; The Lobster Council of Canada; dan Irish Sea Fisheries Board; Western Rock Lobster Council Australia dan perusahaan global seperti Unilever.

Dalam rangka meningkatkan peran Indonesia menjadi pemasok lobster pada pasar global yang 
bersertifikasi, maka pengusaha/pemasok lobster Indonesia harus bergabung membentuk Asosiasi Lobster Indonesia (ALI) atau Konsorsium Lobster Indonesia (KLI). Organisasi ini menjadi wadah untuk mendapat sertfikasi perdagangan lobster Indonesia sesuai dengan prasyarat pasar global. Dengan sertifikasi Marine Stewardship Counciltersebut maka pemasok lobster Indonesia diharapkan dapat mengakses langsung jaringan pasar retail moderen tanpa melalui pihak ketiga serta mampu memasok lobster ke pasar sesuai ukuran, tepat waktu dan jumlah.

\section{Rekomendasi}

ALI atau KLI tersebut diharapkan menjadi pelopor pengembangan kluster bisnis/industri lobster pada daerah/perairan penghasil lobster di Indonesia, membangun pasar lelang lobster berbasis kluster bisnis yang disebutkan diatas dan ikut berperan dalam mengawal serta mensukseskan implementasi berbagai peraturan pemeritah tentang lobster.

\section{PERSANTUNAN}

Terima kasih kepada Kepala Pusat Penelitian Sosial Ekonomi KP yang memberi kepercayaan pada penulis mempelajari perikanan Lobster di Simeulue sejak akhir 2014 sampai 2016. Terima kasih juga kepada: Bapak Muslim Kepala UPT Karantina Ikan Simeulue. Bapak Andre Setiawan (petugas Karantina Ikan Batam), Bapak Swisman (petugas Karantina Ikan Kabupaten Simeulue), Bapak Johan Labay pedagang besar lobster Simeulue serta Bapak Nur Wahyudin pelaku usaha lobster Desa Sepanjang Kecamatan Tanjungsari Gunung Kidul. Informasi dan data dari mereka memperkaya substansi tulisan ini.

\section{DAFTAR PUSTAKA}

Arabiun, A. (2010). Social contractionism and social contructivism. Faculty of Enterpreneurship. (p 14). Tehran Univ. https://www.slideshare.net/edavari / social -4447398. retrived 30 August 2017.

Berger, P.L. \& Luckmann, T. (1966). The social construction of reality. A treatise in the sociology of knowledge. (p. 249). Penguin Books.

BIM. (2010). European Lobster, Homarus gammarus. Handling and Quality Guide. (p. 20). Irish Sea Fisheries Board.

Bell, F.W. (1978). Food from the Sea: The Economics and Politics of Ocean Fisheries. (p 380). Westview
Special Studies in Natural Resources and Energy Management.

Campbell, D., Julie, S., \& Archambault, E. (2013). Cross Cutting Analysis of Scientific Publications Versus other Science, Technology and Innovation Indicator. (p. 72). Luxemberg Publication Office of the UE.

Common Fisheries Policy. (2017). Fact sheet on The European Union. .http://www.europarl.europa.eu / ftu/pdf/en/FTU_5.3.1.pdf. pp 5. Retrived dated: 27 Nop 2017.

Chodrijah, U., Priatna, A \& Nugroho, D. (2018). Distribusi ukuran panjang dan parameter populasi lobster lumpur (Panulirus polyphagus Herbst, 1793) di perairan Sebatik Kalimantan Utara (WPPNRI-716). J.Lit. Perik. Ind. 24(1), 11-23.

Damora, A. (2016). Optimasi pemanfaatan sumberdaya lobster pasir (Panulirus homarus) dalam kerangka ekologi ekonomi di Kabupaten Gunung Kidul dan sekitarnya. Master Tesis. Sekolah Pasca sarjana IPB.

Damsa \& Indrayani. (2018). Pengantar Sosiologi Pasar. (p. 278). Prenadamedia Group.

Davies, D. (2006). Western Australia Rock Lobster. (p. 1) Western Rock Lobster Council. Australia.

Departemen of Fisheries Government of Western Australia. (2014). West Coast Rock Lobster Harvest Strategy and Control Rule 2014 - 2019. (p. 8). Fisheries Management paperno. 264.

(2013).

West Coast Rock Lobster Harvest Strategy and Control Rule 2014 - 2019. Fisheries Management paper no. 263, a discussion paper. http:// w w w. fis h.wa.gov. a u/Documents/ management_papers/fmp263.pdf.

DJPB. (2013). Sentra produksi lobster budidaya air laut di Indonesia. Buku Statistik Perikanan Budidaya Indonesia. Jakarta. KKP.

Dow, R.L., Frederick, W.B. \& Harriman, D.H. (1975). Bioeconomic relationships for Maine Lobster Fishery with consideration of alternative management schemes. Technical Report of National Oceanic and Atmospheric Administration. NMSF SSRF 683. 
Erlania, Radiarta, I.N \& Haryadi, J. (2016). Status Pengelolaan Sumberdaya Benih Lobster untuk Mendukung Perikanan Budidaya: Studi Kasus Perairan Pulau Lombok. J. Kebijakan Perikanan Indonesia (8):2, $85-96$.

Erlania, Radiarta, I.N. \& Sugama, K. (2014). Kelimpahan benih lobster (Panulirus spp.) di Perairan Teluk Gerupuk, Nusa Tenggara Barat: tantangan pengembangan teknologi budidaya Lobster. J. Riset Akuakultur (9):3, 475 - 486.

FAO. (2015). Total World Lobster Production by Country and Origin. Fistat J. Rome. FAO.

Globefish Highlight. (2017). Strong Supply my Put Pressure on Price. (p. 54.). January 2017. Rome FAO.

Hart, G. (2009). Final Report. Assessing the SouthEast Asia Tropical Lobster Supply and Major Market Demand. (p. 55). SADI-ACIAR Research Report. Canberra. ACIAR.

Jones, C. (2010). Tropical Spiny Lobster Aquaculture Development in Vietnam, Indonesia and Australia. J. Mar. Biology. Ass. India. (52) 2, July-Dec 2010, $304-315$.

Jones, C. (2015). Spiny Lobster Aquaculture Development in Eastern Indonesia, Vietnam and Australia. (p. 52). ACIAR Final Report. Canberra. ACIAR.

Josupeit, H., Wang, W. \& Dent, F. (2017). European price report. (p. 24). Rome - FAO.

Kalih, L.A.T.T.W.S. (2012). Keragaman serta distribusi lobster anggota spesies Palinuridae dan Scyllaridae di perairan pantai pulau Lombok. Master Tesis Program Pasca Sarjana, Program Studi Biologi, Fakultas Biologi UGM. Jogjakarta.

Marine Stewardship Council. (2015). Get Certified!. Your Guide to the MSC Fisheries Assessment Process. www.msc.org. pp. 13 retrieved dated: 28 November 2017.

Marine Fisheries Commonwealt of Massachusetts. (2012). Analysis of law, regulations and policies pertaining to the processing, possession and sale of Processed Frozen Lobster part. (p.40). Massachusetts Dept. of Fish and Game.
Nasution, Z., Zulham, A., Manadiyanto, Erlina M.D., Pranowo, S.A., Kurniasari, N.A., Muhartono, R., Istiana., Kurniawan, R., Yanti, B.V.I., Nurlaili \& Yuliati, C. (2015). Kajian penguatan kelembagaan restocking lobster berbasis masyarakat. (p. 232). Jakarta. Laporan Penelitian, PPSEKP.

Nurfiarini, A., Wijaya, D., Mujiyanto., Satria, F., \& Kartamihardja, E.S. (2016). Pendekatan sosialekologi untuk penilaian kesesuaian lokasi restocking lobster pasir, Panulirus homarus (Linnaeus, 1758) pada beberapa perairan di Indonesia. J.Lit.Perik.Ind. 22 (2), 123-138.

Nurfiarini, A \& Purnamaningtyas, S.E. (2017). Pencatatan kedua dan beberapa aspek biologi lobster batik merah, (Panulirus longipes femoristriga Von Marten, 1872) yang ditangkap di Teluk Sepi, Lombok Barat. J.Lit.Perik.Ind. 23(3), $141-152$.

OECD. (2014). Mainstreaming Cross Cutting Issue, 7 lessons from DAC Peer Reviews. OECD Publication. (p. 40). www.oecd.org/publishing/ corrigenda.

Overton, P. (2016). Lobster exporters looking to EU customers for help in averting ban business. http:/ /www.pressherald.com/2016/09/16/ lobsterexporters-looking-to-eu-customers-for-help-indiverting-ban/ retrived dated 31 August 2017.

Permana, A. (2017). Kegiatan penangkapan lobster hijau pasir (Panulirus homarus, Linnaeus, 1758) berkelanjutan di Teluk Palabuhanratu. Master Tesis. Sekolah Pasca Sarjana. Bogor. IPB.

Pereira, G. \& Josupeit, H. (2017). The World Lobster Market. Globefish Research Programme. Vol 123. (p. 41). Rome. FAO.

Pretty, J. (1995). Regenerative Agriculture: Policies and Practice for Sustainability and Self Reliance. London, Earthscan. In R. Ramizes. (Eds). Participatory Learning and Communication Approaches for Managing Pluralism. Retrieved from http://www.fao.org/ documents /show_ cdr. asp ?url_file=/DOCREP?W8827E/w8827e08.htm.

Radcliffe-Brown, A.R. (1940). On Social. The Journal of Antrophological Institute of Great Britain and Ireland. (70)1. 1940, 1-12. 
Romdhon, M.M. \& Sukiyono K. (2011). Pola kemitraan pemasaran lobster di Kota Bengkulu. AGRISEP. $10(1), 126-137$.

Saptana \& Ashari. (2007). Pembangunan kemitraan berkelanjutan melalui kemitraan usaha. Jurnal Litbang Pertanian. (26)4, 123 - 130.

Setyono, D.E.D. (2006). Budidaya pembesaran udang karang (Panulirus spp.). Oceana (XXXI).4, 39 - 48.

Suantika, G, Azizah, F.F.N. \& Hasby, F.A. (2017). Aplikasi teknologi hybrid-zero water discharge untuk budidaya lobster air laut di Cidaun, Cianjur, Jawa Barat. (p.30). Laporan penelitian LPPM ITB.

The Lobster Council of Canada. (2017). Works to enhance the value of the Canadian Lobster Sector in a sustainable manner. http:// lobstercouncilcanada.ca/. retrieved 5 April 2018.

Wardiatno, Y., Hakim, A.A., Mashar, A., Butet, N.A., Adrianto, L., \& Fajarallah, A. (2016). On the presence of Andaman Lobster, Metanephrops andamicus (Wood - Mason, 1891) (Crustacea Astacidea Neprophidae in Palabuhanratu Bay (SJava, Indonesia). Biodiversity Journal. (7).1, 17 20.

Williams, K.C. (2009). Spiny lobster aquaculture in the Asia Pacific Region. Proceedings of an International symposium held at Nha Trang. Vietnam, 9-10 December 2008. (p.162). ACIAR Proceeding no. 132. Canberra. ACIAR.

Witomo, C.M. \& Nurlaili. (2015). Strategi keberlanjutan pengelolaan bibit lobster di Perairan Lombok. J. Kebijakan Sosek KP. (5).1, 11 - 18.

Zulham, A. \& Nasution, Z. (2016). Bisnis lobster di Simeulue: keragaan perdagangan dan kebijakan inovasi budidaya. J. Kebijakan Sosial Ekonomi KP. (6).2, $153-164$.

Zulham, A., Adi, T.R., Triyono., Oktariani, D., \& Arthatiani, F.Y. (2015). Sentra Inovasi Teknologi dan Bisnis Kelautan dan Perikanan Simeulue. (p.40). Laporan Akhir Kegiatan. BBPSEKP. 